\title{
Stromelysin-3 Expression Promotes Tumor Take in Nude Mice
}

\author{
Agnès C. Noël,, Olivier Lefebvre, ${ }^{\star}$ Erik Maquoi, ${ }^{*}$ Leen VanHoorde,,$\$$ Marie-Pierre Chenard,ף Marc Mareel,§ \\ Jean-Michel Foidart, ${ }^{\ddagger}$ Paul Basset, ${ }^{\star}$ and Marie-Christine Rio* \\ *Institut de Génétique et de Biologie Moléculaire et Cellulaire (IGBMC), Centre National de la Recherche Scientifique/Institut National de \\ la Santé et de la Recherche Médicale U184/Université Louis Pasteur, BP 163, 67404 Illkirch Cedex, C.U. de Strasbourg, France; \\ ${ }^{\ddagger}$ Laboratory of General Biology, University of Liège, 4000 Sart-Tilman, Liège, Belgium; ${ }^{\S}$ Laboratory of Experimental Cancerology, \\ University Hospital, Ghent, B-9000, Belgium; and "Service d’Anatomie Pathologique Générale, Centre Hospitalier Universitaire de \\ Hautepierre, 67098 Strasbourg Cedex, France
}

\begin{abstract}
Stromelysin-3 (ST3) is a matrix metalloproteinase expressed in human carcinomas in ways suggesting that it may play a role in tumor progression. To test this possibility, we have performed gene transfer experiments using both anti-sense and sense ST3 expression vectors, and malignant cells either expressing (NIH 3T3 fibroblasts) or not (MCF7 epithelial cells) endogenous ST3. We have compared the ability of parental and transfected cells to cause subcutaneous tumor development in nude mice. 3T3 cells expressing anti-sense ST3 RNA showed reduced tumorigenicity, and MCF7 cells expressing mouse or human ST3 were associated with reduced tumor-free period leading to a significant increased tumor incidence $\left(P<10^{-4}\right)$. However, once established, the ST3-expressing tumors did not grow faster than those obtained with the parental MCF7 cell line. In addition, tumors obtained after sub-cutaneous injection of ST3-expressing or nonexpressing cells did not exhibit obvious histological differences, and careful examination did not reveal any local invasive tissue areas nor systemic metastases. These in vivo observations were in agreement with those obtained in vitro showing that ST3 expression did not modify proliferative nor invasive properties of transfected cells. Altogether, these results indicate that ST3 expression promotes tumor take in nude mice, presumably by favoring cancer cell survival in a tissue environment initially not permissive for tumor growth. These findings represent the first experimental evidence showing that ST3 can modulate cancer progression. (J. Clin. Invest. 1996. 97:1924-1930.) Key words: cancer cell invasion/survival - metalloproteinases • tumorigenicity
\end{abstract}

\section{Introduction}

Matrix metalloproteinases (MMPs) ${ }^{1}$ are members of a family of zinc-dependent endopeptidases with a broad spectrum of proteolytic activities toward extracellular matrix (ECM) components (1-3). These enzymes include collagenases, gelati-

A. Noël and O. Lefebvre should be considered as equal first authors. Address correspondence to Marie-Christine Rio, IGBMC, BP 163, Illkirch Cedex, 67404, France. Phone: 88-65-34-24; FAX: 88-6532-01.

Received for publication 27 November 1995 and accepted in revised form 31 January 1996.

J. Clin. Invest.

(C) The American Society for Clinical Investigation, Inc. 0021-9738/96/04/1924/07 \$2.00

Volume 97, Number 8, April 1996, 1924-1930 nases, stromelysins, and membrane-type MMPs (1-7). They are expressed as proenzymes which are processed to active forms through proteolytic cleavage, and their activities are controlled by physiological tissue inhibitors of metalloproteinases (TIMPs). It has been proposed that imbalance between MMPs and TIMPs is implicated in various physiological and pathological tissue remodeling processes, notably those enabling tumor progression and leading to metastasis (8-9). Experimental evidences supporting this possibility were presented by Khokha et al. (10) who demonstrated that the down-regulation of TIMP-1 levels by anti-sense (AS) RNA transfection in 3T3 cells increased their tumorigenic and metastatic potential in nude mice. Inversely, the secretion of functional TIMP-2 in stably transfected cells was found to result in a marked decrease in tumor growth rate and local invasiveness (11). More recently, matrilysin over-expression in human prostate cancer cells was reported to increase their invasive potential in SCID mice (12). Gene transfer experiments using both sense (S) and AS expression vectors have also shown that the level of matrilysin expression was a critical factor in the aptitude of colon cancer cells to migrate through basement membrane-like matrices in vitro (13) and to generate tumors in vivo, in nude mice (14). Similarly, the expression of gelatinase A or B was found to confer a metastatic phenotype to transfected transformed cells $(15,16)$.

Stromelysin-3 (ST3) was first described in fibroblastic cells of invasive breast carcinoma and classified as a member of the MMP family on the basis of sequence homologies (17). ST3 expression was thereafter observed in most other types of human invasive carcinomas and in some precursor lesions $(18,19$, and references therein). Strong ST3 gene expression has been correlated with increased local aggressiveness of tumors $(20,21)$, and high levels of ST3 RNA were found to be predictive of recurrence in breast carcinomas (22). ST3 over-expression was also shown to be associated with tissue remodeling occurring in physiological conditions such as embryonic development (23), amphibian metamorphosis (24), mammary gland involution (25), wound healing (20), and cycling endometrium (26). Although these observations suggest that ST3 may play a role in ECM remodeling, putative mature forms of human ST3 (hST3) appear unable to degrade any major ECM component $(27,28)$. Furthermore, it has been recently demonstrated that ST3 was predominantly secreted as a potentially active form, pro-ST3 being intracellularly processed by a furin-dependent proteolytic cleavage (29). ST3 thus differs from other MMPs which must be activated extracellularly, indicating that ST3

1. Abbreviations used in this paper: AS, anti-sense; ECM, extracellular matrix; h, m ST3: human, mouse stromelysin-3; MMP, matrix metalloproteinase; S, sense; S.C., subcutaneous; TIMP, tissue inhibitor of metalloproteinase. 
may have a unique role in tissue remodeling processes, including those associated with tumor progression.

In the present study, we have subcutaneously (S.C.) injected nude mice with malignant cells stably transfected with either AS or S ST3 cDNA constructs, in order to evaluate the effect of ST3 expression on tumorigenicity in vivo. Using the same cells, we have also tested whether ST3 could modulate cell proliferation and invasion in vitro.

\section{Methods}

Construction of anti-sense and sense ST3 expression vectors. The $p C M V A S-$ mST3 plasmid was obtained by inserting in the AS orientation, a 360bp BamHI fragment (nucleotides 1 to 360 ) of mouse ST3 (mST3) cDNA (24) into the $p C M V$ vector in which expression is under the control of the cytomegalovirus (CMV) promoter (provided by B. Vogelstein, Baltimore, MD) (30). To generate the $p C M V m S T 3$ plasmid, a 1504-bp NsiI fragment, containing the entire coding sequence of mST3, was excised and ligated to a 8-mer BamHI-NsiI adaptor and subcloned in the $\mathrm{S}$ orientation into the BamHI site of the $p C M V$ vector. To generate the $p C M V h S T 3$ plasmid, a 1680-bp SpeI-XhoI fragment of hST3 cDNA (17), containing the entire coding sequence, was inserted in S orientation into the compatible NheI/XhoI sites of the $p C M V$ vector modified by insertion of a polylinker containing BamHI, NheI, and XhoI restriction sites. To generate the pSG5hST3 plasmid, a 1681 bp EcoRI fragment of hST3 cDNA was inserted in S orientation into the EcoRI site of the $p S G 5$ vector in which expression is under the control of the SV40 promoter (31).

Obtention of stably transfected cell lines. Malignant NIH 3 T3 (obtained from B. Pettmann, Strasbourg, France) (32) and MCF7 (ATCC HTB 22) cells were cultured in Dulbecco's modified Eagle's medium (DME) containing $10 \%$ fetal calf serum. 3T3 cells were electroporated with linearized $p C M V A S m S T 3$ construct $(10 \mu \mathrm{g})$ or linearized $p C M V$ vector alone $(10 \mu \mathrm{g})$, using a BioRad apparatus at 400 volts and $125 \mu \mathrm{F}$. Similar conditions were used for MCF7 cell transfection with linearized $p C M V m S T 3$ or $p C M V h S T 3 \mathrm{~S}$ constructs, or linearized $p C M V$ vector alone. Linearized $p S G 5 h S T 3 \mathrm{~S}$ construct $(8 \mu \mathrm{g})$ was co-transfected into MCF7 cells with linearized $p S V 2$ neo vector (ATCC 37149) $(2 \mu \mathrm{g})$. Transfectants were then selected with the neomycin analogous G418 (400 $\mu \mathrm{g} / \mathrm{ml}$; GIBCO BRL, Gaithersburg, MD) through the neomycin-resistance gene of the $p C M V$ vector, or through the cotransfected $p S V 2$ neo vector.

$R N A$ isolation and analysis. Total RNA was prepared from cultured cells using acid guanidinium thiocyanate-phenol-chloroform extraction (33). RNAs were fractionated by electrophoresis through $1 \%$ agarose gel in the presence of formaldehyde, and transferred to nylon membranes (Hybond N; Amersham). Filters were acidified for $10 \mathrm{~min}$ in $5 \% \mathrm{CH} 3 \mathrm{COOH}$ and stained for $10 \mathrm{~min}(0.004 \%$ methylene blue, 0.5 M CH3COONa, pH 5.0) before hybridization. Northern blots were hybridized under stringent conditions $\left(50 \%\right.$ formamide, $\left.42^{\circ} \mathrm{C}\right)$ with mST3 (24), hST3 (17) and 36B4 (34) cDNA probes ${ }^{32} \mathrm{P}$-labeled by random priming. Washings were performed in $2 \times \mathrm{SSC}, 0.1 \%$ SDS at $22^{\circ} \mathrm{C}$, followed by $0.1 \times \mathrm{SSC}, 0.1 \%$ SDS at $55^{\circ} \mathrm{C}$.

Protein analysis. Conditioned media were obtained by incubating subconfluent cells in serum-free DME. After $48 \mathrm{~h}$ incubation, media were collected, cleared by centrifugation at $5000 \mathrm{~g}$ for $30 \mathrm{~min}$ and precipitated at $4{ }^{\circ} \mathrm{C}$ with $80 \%$ ammonium sulfate. After centrifugation at $10000 \mathrm{~g}$ for $2 \mathrm{~h}$, protein pellets were resuspended in $50 \mathrm{mM}$ Tris- $\mathrm{HCl}$ (pH 7.4), $100 \mathrm{mM} \mathrm{NaCl}, 5 \mathrm{mM} \mathrm{CaCl}, 1 \mu \mathrm{M} \mathrm{ZnCl}_{2}$ and dialyzed against this buffer at $4^{\circ} \mathrm{C}$, for $3 \mathrm{~h}$. Protein concentrations were determined using the BioRad kit (BioRad Laboratories). Protein samples were analyzed by SDS-PAGE (12\%) under reducing conditions. For immunoblot analysis, proteins were transferred after electrophoresis to nitrocellulose filters which were incubated with monoclonal antibody 5ST-4C10 which recognizes the ST3 catalytic domain (35). Bound antibodies were visualized using a peroxidase-labeled goat an- tibody raised against mouse $\mathrm{IgG}$, followed by Enhanced Chemiluminescence detection (ECL kit; Dupont NEN, Boston, MA).

Tumorigenicity assay. Subconfluent NIH 3T3 cells were trypsinized, centrifugated at $1000 \mathrm{~g}$ for $5 \mathrm{~min}$, and resuspended in serum-free DME. A total volume of $0.2 \mathrm{ml}$ containing $5 \times 10^{5}$ cells was S.C. injected into 6-8-week-old female nude MF1 nu/nu mice (Harlan, France). Subconfluent MCF7 cells were trypsinized, washed twice, and harvested by centrifugation at $1000 \mathrm{~g}$ for $5 \mathrm{~min}$. Cells resuspended in cold serum-free DME were mixed with an equal volume of cold matrigel $(10 \mathrm{mg} / \mathrm{ml})$ prepared from the Engelbreth-HolmSwarm tumor, as previously described (36). A total volume of $0.5 \mathrm{ml}$ containing $5 \times 10^{4}$ cells was S.C. injected into 6-8-week-old female nude mice, previously implanted with Silastic capsules (Dow Corning) containing estradiol (37).

Injected mice were examined every $2 \mathrm{~d}$ for tumor apparition and tumor volume was calculated as previously described (37). Tumor incidence was defined as the percentage of mice presenting a tumor, in considering only tumors having a volume of at least $100 \mathrm{~mm}^{3}$. The data were statistically analyzed with the log Rank test (38). $P$ values lower than 0.05 were considered as significant. All mice were autopsied. One half of each tumor was immediately frozen in liquid nitrogen for RNA analysis. The second tumor half, the lungs and the liver were fixed in phosphate buffered formalin $(4 \%)$ and embedded in paraffin. Histological examination was performed on hematoxilineosin stained sections. Immunohistochemical localization of mST3 was performed using polyclonal antibody 612 , obtained by rabbit immunization with recombinant $\mathrm{mST} 3$ extracted from bacterial inclusion bodies (28), whereas the immunohistochemical localization of hST3 was performed using rabbit polyclonal antibody 349 as previously described (21). Tissue sections were also stained with a rabbit polyclonal antibody raised against human pS2 (39), in order to check for the presence of metastatic MCF7 cells in mouse lungs and liver.

Cell proliferation and in vitro invasion assays. Cell proliferation was evaluated by counting trypsinized cells every $2 \mathrm{~d}$ using a Coulter counter (Coultronics France).

Chemoinvasion assays (40) were performed using Transwell chambers (Costar Corp., Cambridge, MA) with polycarbonate membrane filters $(6.5 \mathrm{~mm}$ diameter, $8 \mu \mathrm{m}$ pore size $)$ coated with matrigel $(50 \mu \mathrm{g} /$ filter $)(35)$. Cells $\left(3 \times 10^{4}\right)$ were harvested by trypsinization, resuspended in serum-free DME containing $0.2 \%$ bovine serum albumin (ICN, Flow) and added to the upper compartment of Transwell chambers. The lower compartment was filled with $600 \mu \mathrm{l}$ DME containing $20 \%$ fetal calf serum and $2 \%$ bovine serum albumin as chemoattractants. After 48 or $72 \mathrm{~h}$ of incubation at $37^{\circ} \mathrm{C}$, filters were rinsed in phosphate buffered saline, fixed in paraformaldehyde $4 \%$ and permeabilized in ice-cold methanol before staining with hematoxylin-eosin. Cells on the upper face of the filters were wiped away with a cotton swab, and those on the lower face were counted on 24 fields/filter at a magnification of $\times 400$. Three independent experiments were conducted, each using three Transwell chambers.

For collagen invasion assays, cells were seeded onto a polymerized type I collagen gel. After $24 \mathrm{~h}$ incubation at $37^{\circ} \mathrm{C}$, the number of cells that had invaded into the collagen gel was counted as previously described (41).

Invasion assays into chick heart were based on the in vitro confrontation between cell aggregates and precultured chick heart fragments in organ culture (42). The interaction between tested cells and chick heart fragments was evaluated by microscopic examination of serial sections fixed in Bouin Holland's solution, embedded in paraffin, and stained with hematoxylin and eosin.

\section{Results}

Decreased tumor incidence using cells down-regulated for mST3 expression. A malignant mouse NIH 3T3 fibroblastic cell line, which constitutively expresses mST3 RNA (Fig. 1, lane 1), was stably transfected with the $p C M V A S m S T 3$ vector (see Meth- 


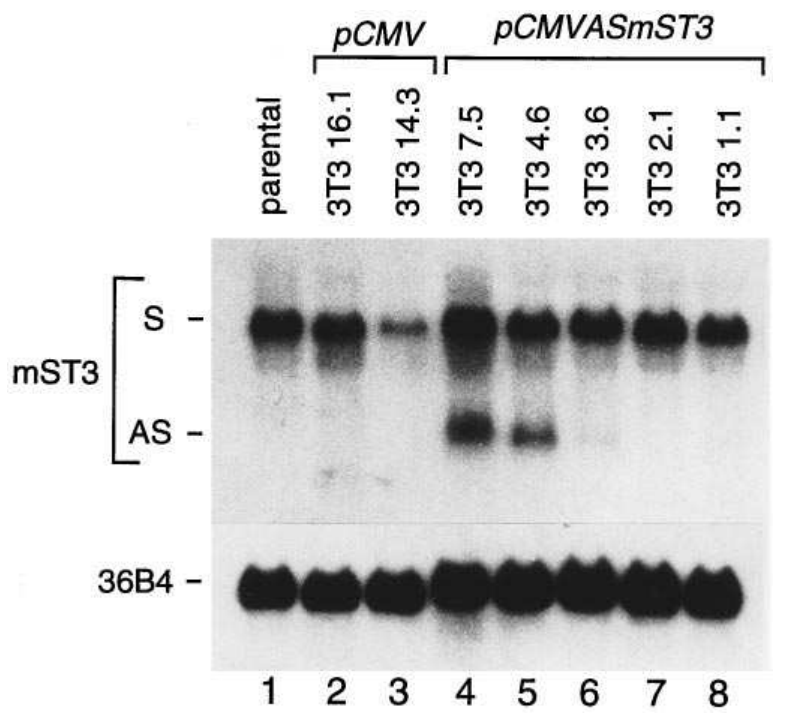

Figure 1. Northern blot analysis of NIH 3 T3 cells transfected with an AS mST3 cDNA construct. (Lane 1) parental cells; (lanes 2 and 3) $p C M V$ transfected cells; (lanes 4-8) pCMVASmST3 transfected cells. The position of the endogenous sense (S) and exogenous anti-sense (AS) mST3 transcripts are indicated. The 36B4 probe was used as a control for loading and transfer; autoradiography was for $2 \mathrm{~d}$ (mST3) and $18 \mathrm{~h}(36 \mathrm{~B} 4)$.

ods) in order to downregulate the expression of the mST3 endogenous gene. Different neomycin resistant clones were established. Three of them were found to express AS transcripts with the expected size, either at high (3T3/7.5 and 3T3/4.6) or low (3T3/3.6) levels (Fig. 1, lanes 4-6). The other clones, including the 3T3/2.1 and 3T3/1.1 clones, did not express AS transcripts (Fig. 1, lanes 7 and 8 ). In addition, the NIH 3T3 cell line was transfected with the $p C M V$ vector alone and gave rise to the 3T3/16.1 and 3T3/14.3 control clones (Fig. 1, lanes 2 and 3).

Nude mice were S.C. inoculated with an identical number of cells of each clone. After $3 \mathrm{wk}$, tumors were observed in 50 and $20 \%$ of injection sites for the parental NIH 3 T3 cell line, and the 3T3/16.1 control cells, respectively (Table I). At 6 wk, the tumor incidence for these 2 cell lines reached $80 \%$ and
$100 \%$, respectively, demonstrating their high propensity to implant and proliferate into nude mice. Surprisingly, the second control clone, $3 \mathrm{~T} 3 / 14.3$, did not give rise to any tumor until 6 wk after cell injection, and led to a tumor incidence of only $14 \%$ at 8 wk (Table I). However, as shown in Fig. 1 (lane 3), the endogenous mST3 RNA level of this clone was much lower than those of the other 3T3 clones, suggesting clonal variation in the parental $3 \mathrm{~T} 3$ cell population, or that a recombination event leading to decreased ST3 gene expression, has occurred during transfection of these cells. Among the pCMVASmST3 transfected cells, the clones 3T3/3.6, 3T3/2.1 and 3T3/1.1, which expressed very low levels or no AS mST3 RNA (Fig. 1, lanes 6-8), behaved similarly to the parental cell line, although tumor appearance was slightly delayed with the 3T3/1.1 clone, which exhibited a tumor incidence of $71 \%$ after 8 wk of observation (Table I). The two other clones (3T3/7.5 and 3T3/4.6), however, exhibited a different pattern. First, no tumor could be detected 3 wk after cell injection. Second, tumor numbers were still low at $6(14-20 \%)$ and at $8(30-57 \%)$ weeks (Table I). Since these clones expressed the highest levels of AS mST3 RNA (Fig. 1, lanes 4 and 5), these findings suggested that decreased mST3 expression could explain their reduced tumorigenicity. Low levels of $\mathrm{mST} 3$ secretion by parental 3 T3 cells together with a poor stability of $\operatorname{mST} 3(28,43)$ did not permit to precisely quantify the decrease in $\mathrm{mST} 3 \mathrm{se}$ cretion in $3 \mathrm{~T} 3$ cells transfected with AS mST3 RNA. However, using Western blot analysis, we could detect a low molecular weight form of mST3 at $28 \mathrm{kD}$ in 4 out of 10 samples of culture media conditioned by parental 3 T 3 cells, but in none ( 0 out of 10) of those obtained from 3T3/7.5 transfected cells (data not shown).

To further investigate the contribution of ST3 to tumorigenicity, we performed reverse experiments in which MCF7 cells, which do not express the endogenous ST3 gene (Fig. $2 \mathrm{~A}$, lane 1 ), were stably transfected with a $\mathrm{S} \mathrm{mST} 3 \mathrm{cDNA}$ in order to produce recombinant $\mathrm{mST} 3$.

Increased tumor incidence using cells over-expressing mST3. MCF7 breast cancer cells were stably transfected with the $p C M V m S T 3$ vector (Methods), and neomycin resistant clones were screened for expression of mST3 using Northern blot analysis. Three clones were found to express high (MCF7mST3/1 and MCF7mST3/11; Fig. $2 A$, lanes 2 and 3) or

Table I. Tumorigenicity of Parental, pCMV and pCMVASmST3-transfected NIH 3T3 Cells, after S.C. Injection into Nude Mice

\begin{tabular}{|c|c|c|c|c|c|c|}
\hline \multirow[b]{2}{*}{ Clones } & \multirow[b]{2}{*}{ Transfected vector } & \multirow[b]{2}{*}{ S RNA* } & \multirow[b]{2}{*}{ AS RNA* } & \multicolumn{3}{|c|}{ Tumor incidence after injection ${ }^{\ddagger}$} \\
\hline & & & & $3 \mathrm{wk}$ & $6 \mathrm{wk}$ & $8 \mathrm{wk}$ \\
\hline $3 \mathrm{~T} 3$ & - & + & - & $5 / 10(50 \%)$ & $8 / 10(80 \%)$ & $9 / 10(90 \%)$ \\
\hline 3Т3/16.1 & $p C M V$ & + & - & $1 / 5(20 \%)$ & $5 / 5(100 \%)$ & $5 / 5(100 \%)$ \\
\hline 3Т3/14.3 & $p C M V$ & $+/-$ & - & $0 / 7(0 \%)$ & $0 / 7(0 \%)$ & $1 / 7(14 \%)$ \\
\hline $3 \mathrm{~T} 3 / 7.5$ & $p C M V A S m S T 3$ & + & + & $0 / 10(0 \%)$ & $2 / 10(20 \%)$ & $3 / 10(30 \%)$ \\
\hline 3T3/4.6 & $p C M V A S m S T 3$ & + & + & $0 / 7(0 \%)$ & $1 / 7(14 \%)$ & $4 / 7(57 \%)$ \\
\hline $3 \mathrm{~T} 3 / 3.6$ & pCMVASmST3 & + & $+/-$ & $3 / 7(43 \%)$ & 7/7 (100\%) & $7 / 7(100 \%)$ \\
\hline $3 \mathrm{~T} 3 / 2.1$ & pCMVASmST3 & + & - & $6 / 12(50 \%)$ & $9 / 12(80 \%)$ & $11 / 12(92 \%)$ \\
\hline 3T3/1.1 & $p C M V A S m S T 3$ & + & - & $1 / 7(14 \%)$ & $3 / 7(43 \%)$ & $5 / 7(71 \%)$ \\
\hline
\end{tabular}

*S and AS mST3 RNA expression was evaluated by Northern blot analysis as illustrated in Fig. 1; (+), high, $(+/-)$, low and $(-)$, undetectable levels. ¥Each ratio in the table represents the number of tumors larger than $100 \mathrm{~mm}^{3} \mathrm{vs}$. the total number of injected mice, at the indicated time after cell injection; corresponding percentages are indicated in parentheses. 
A

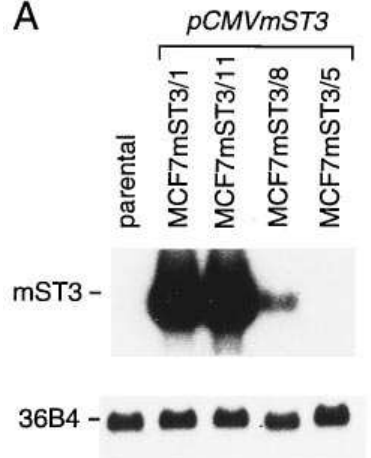

$\begin{array}{lllll}1 & 2 & 3 & 4 & 5\end{array}$
B

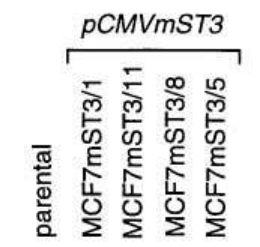

$\mathrm{kD}$

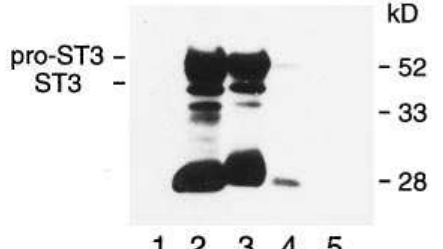

$\begin{array}{lllll}1 & 2 & 3 & 4 & 5\end{array}$

C

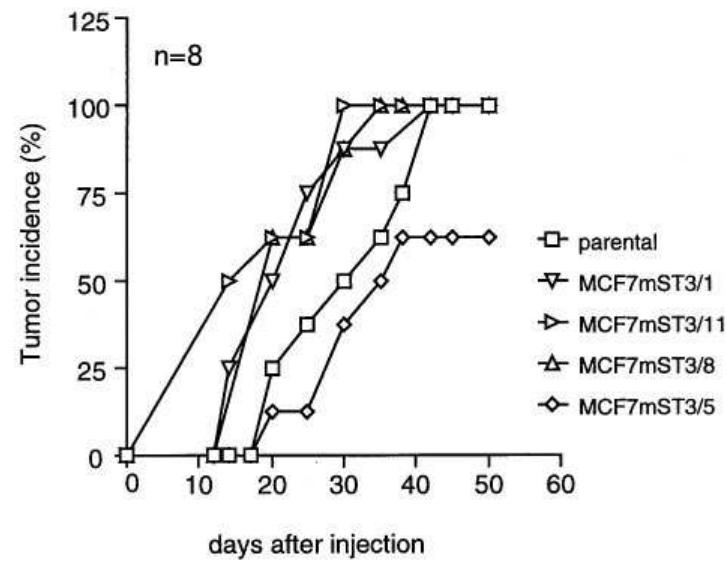

Figure 2. Analysis of MCF7 cells expressing exogenous mST3 under the control of the CMV promoter. $(A)$ Northern blot analysis: autoradiography was for 1 day (mST3) and $18 \mathrm{~h}$ (36B4). (B) Western blot analysis of conditioned media: the positions of molecular weight standards, and of pro- and mature ST3 are indicated on the right and left, respectively. ( $A$ and $B$ ) lane 1, parental cells; lanes $2-5, p C M V m S T 3$ transfected cells. (C) tumor incidence after S.C. injection of parental and $p C M V m S T 3$ transfected MCF7 cells; $\mathrm{n}$ indicates the number of injected mice for each cell clone.

moderate (MCF7mST3/8; Fig. $2 A$, lane 4) levels of mST3 RNA, whereas we could not detect any mST3 RNA in the MCF7mST3/5 clone (Fig 2. A, lane 5), even after a longer exposure time (data not shown). By Western blot analysis, we could detect $\mathrm{mST} 3$ protein in culture media conditioned by MCF7mST3/1, MCF7mST3/11 and MCF7mST3/8 cells (Fig. 2 $B$, lanes 2-4), but not by MCF7mST3/5 cells (Fig. $2 B$, lane 5). Both pro- and mature mST3 forms were detected together with some degradation products, including the $28-\mathrm{kD}$ form.

In vivo tumorigenicity of these cells was tested by S.C. injection in nude mice. As shown in Fig. $2 C$, the tumor incidence in mice injected with MCF7 cells expressing mST3 was significantly increased ( $\log$ Rank test, $P<2 \times 10^{-5}$ ). Thus, $20 \mathrm{~d}$ after cell injection, MCF7mST3/1, MCF7mST3/11 and MCF7mST3/ 8 cells gave rise to a tumor incidence of $50-62 \%$, whereas parental MCF7 cells and MCF7mST3/5 cells led to a tumor incidence of 25 and $12 \%$, respectively. This difference in tumor incidence, which was still observed $35 \mathrm{~d}$ after cell injection, was no longer apparent after $40 \mathrm{~d}$ when all cells, excepting MCF $7 \mathrm{mST} 3 / 5$, led to $100 \%$ tumors. Thus, the variation in tumor incidence which was observed in these experiments in fact

A

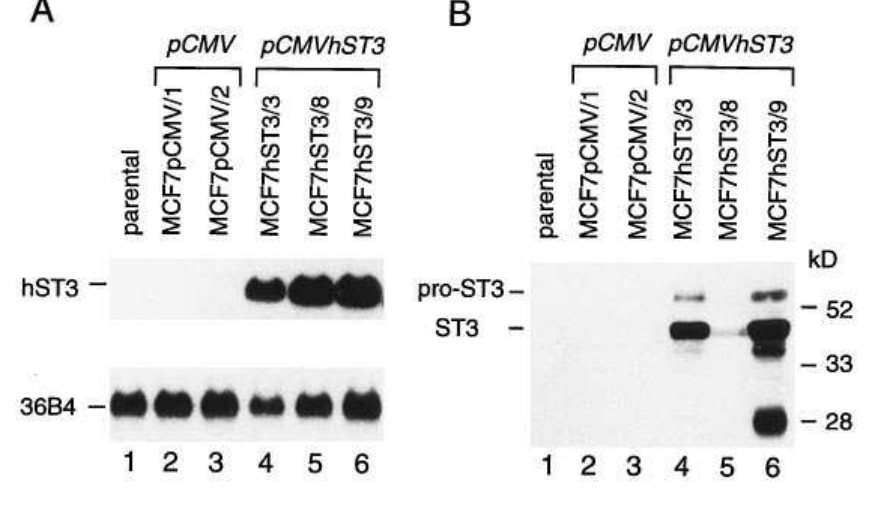

C

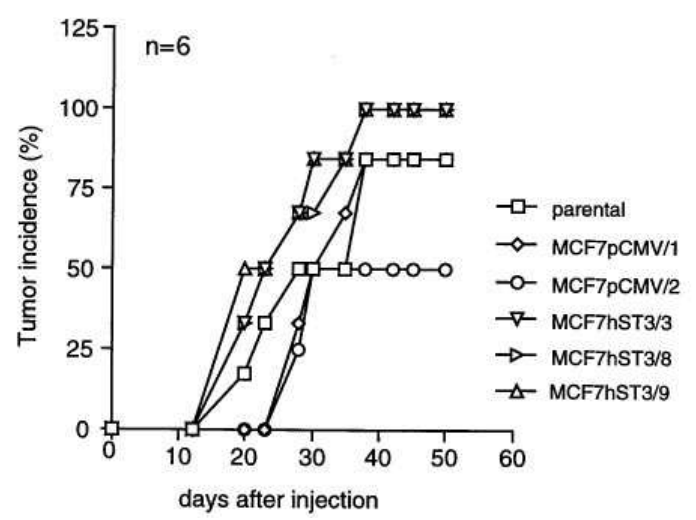

Figure 3. Analysis of MCF7 cells expressing exogenous hST3 under the control of the CMV promoter. $(A)$ Northern blot analysis: autoradiography was for $1 \mathrm{~d}(\mathrm{hST} 3)$ and $18 \mathrm{~h}$ (36B4). (B) Western blot analysis of conditioned media: the positions of molecular weight standards, and of pro- and mature ST3 are indicated on the right and left, respectively. ( $A$ and $B$ ) lane 1 , parental cells; lanes $2-3, p C M V$ transfected cells; lanes 4-6, $p C M V h S T 3$ transfected cells. $(C)$ tumor incidence after S.C. injection of parental, $p C M V$ and $p C M V h S T 3$ transfected MCF7 cells; $n$ indicates the number of injected mice for each cell clone.

corresponds to a reduction of the tumor-free period when mST3-expressing cells were S.C. injected in mice.

These findings were in good agreement with our hypothesis that $\mathrm{mST} 3$ could promote tumorigenicity in nude mice. However, since differences have been observed between the functional properties of $\mathrm{mST} 3$ and hST3 $(28,43)$, we tested whether similar results could be obtained using MCF7 cells expressing hST3.

Increased tumor incidence using cells over-expressing hST3. Using the same protocol as described above, we obtained 3 MCF7 clones stably transfected with the $p C M V h S T 3$ vector and expressing hST3 RNA (MCF7hST3/3, MCF7hST3/8 and MCF7hST3/9; Fig. $3 A$, lanes 4-6). These cells secreted both pro- and mature hST3 in their culture media (Fig. $3 B$, lanes 4-6). In addition, we obtained two control clones (MCF7pCMV/1 and MCF7pCMV/2) transfected with the $p C M V$ vector alone, which did not express hST3 (Fig. 3, $A$ and $B$, lanes 2 and 3). As observed for mST3, hST3 expression was found to promote tumor incidence in nude mice (log Rank test, $P<4 \times 10^{-4}$ ) (Fig. $3 \mathrm{C}$ ). Similar results were also obtained using a clone (MCF7hST3/13) stably transfected with a construct in which hST3 was expressed under the control of the less potent SV40 
A

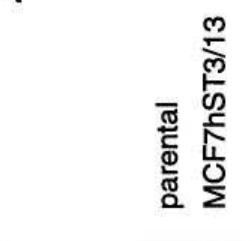

hST3 -

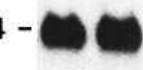

12
B

$\mathrm{kD}$
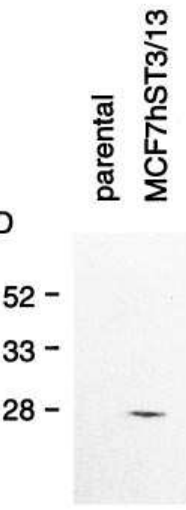

12

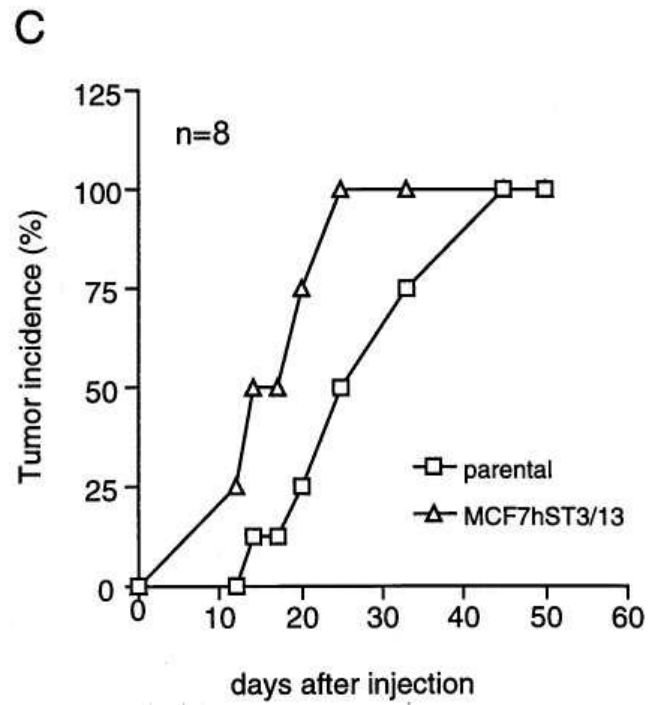

Figure 4. Analysis of MCF7 cells expressing exogenous hST3 under the control of the SV40 promoter. $(A)$ Northern blot analysis: autoradiography was for $4 \mathrm{~d}$ (hST3) and $18 \mathrm{~h}$ (36B4). (B) Western blot analysis of conditioned media: the positions of molecular weight standards are indicated on the left. In panels A and B: lane 1: parental cells; lane 2, pSG5hST3 transfected cells. (C) tumor incidence after S.C. injection of parental and $p S G 5 h S T 3$ transfected cells; $\mathrm{n}$ indicates the number of injected mice for each cell clone.

promoter of the pSG5 vector, instead of the CMV promoter. Low levels of hST3 RNA (Fig. $4 A$, lane 2) and of the hST3 28kD form (Fig. $4 B$, lane 2) could be detected in MCF7hST3/13 cells and culture media, respectively. Despite this low level of hST3 expression, MCF7hST3/13 cells led to an increased tumor incidence $\left(\log\right.$ Rank test, $\left.P<4 \times 10^{-5}\right)$. Thus, $20 \mathrm{~d}$ after cell injection, $75 \%$ of mice injected with MCF7hST3/13 cells exhibited tumors whereas parental MCF7 cells gave rise to only $25 \%$ (Fig. $4 C$ ).

ST3 over-expression did not modify cell growth and invasiveness. To define what could be the process leading to a reduction of the tumor-free period and thus to an increased tumor incidence after S.C. injection of MCF7 cells expressing either mST3 or hST3, we first evaluated tumor growth and cell proliferation rates. We observed that once the tumors were established, the evolution of tumor volumes was identical from one

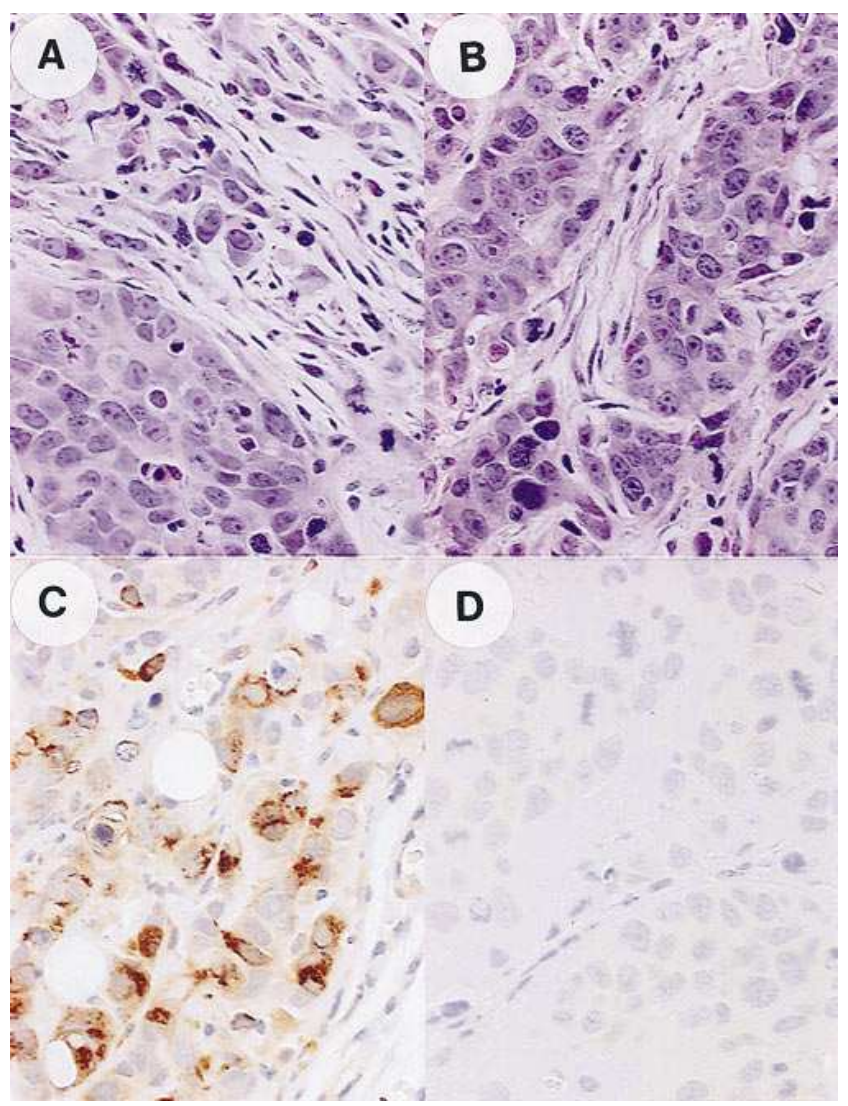

Figure 5. Histological and immunohistological analyses of tumors derived from MCF7hST3/9 and control MCF7pCMV/1 cell clones. Tumor sections were stained with hematoxylin and eosin $(A$ and $B)$ (X 60), or immunostained with polyclonal antibody 349 raised against hST3 $(C$ and $D)(\times 60)$. $(A$ and $C) \mathrm{hST3}$-expressing MCF7hST3/9 cells; $(B$ and $D)$ control MCF7pCMV/1 cells.

cell clone to another, independently of the levels of ST3 expression. Consistently, no major differences were observed for the in vitro cell proliferation rates whether or not the transfected cells expressed mST3 or hST3 (data not shown).

We next tested the invasive properties of transfected MCF7 cells, both in vivo and in vitro. All clones grew as well delineated tumor masses, and no evidence of local invasion could be detected regardless of the tumor size. Moreover, careful anatomopathological examination of mice did not reveal any lung or liver metastases, even after pS2 immunostaining allowing the detection of isolated MCF7 cells (39). No histological differences, notably concerning their vascular status, were observed between tumors obtained in nude mice after injections of either parental MCF7 cells or cells transfected with $p C M V, p C M V m S T 3$ or $p C M V h S T 3$. Although the tumor stroma was not as well developed as that of human breast carcinomas, we could observe areas where tumoral epithelial cells were surrounded by fibroblastic cells after injection of ST3expressing (Fig. $5 A$ ) or control MCF7 cells (Fig. 5 B). Endogenous mST3 could not be detected in these fibroblasts, using antibody 612 directed against mST3 (data not shown). MCF7 cells expressing recombinant ST3 protein were found to be homogeneously distributed throughout tumors, and staining was restricted to the cytoplasm of transfected MCF7 cells (Fig. 5C). Northern blot (data not shown) and immunohistochemical 
(Fig. 5, $C$ and $D$, and data not shown) analyses showed that the levels of tumoral exogenous mST3 and hST3 RNAs and proteins were in good agreement with those observed for the corresponding MCF7 clones, in vitro. Finally, the invasive properties of control and ST3-expressing cells were compared in the type I collagen (41) and chick heart (42) invasion assays. The expression of exogenous ST3 did not modify cell invasiveness. Thus, neither ST3-expressing nor control cells invaded type I collagen gels, and they resulted in the development of an organized non-invasive epithelioid layer at the periphery of the heart tissue. We also tested the capacity of parental and transfected cells to pass through matrigel-coated filters by using Transwell chamber (40). Once again, no significant differences were observed between cells expressing or not mST3 or hST3, suggesting that ST3 expression did not confer cell invasive properties, in these in vitro assays (data not shown).

\section{Discussion}

In the present study, we investigated the role of ST3 in the development of tumors after S.C. injection of malignant cells in nude mice. We demonstrated that the incidence of tumors obtained using malignant mouse fibroblastic NIH 3T3 cells, which endogenously express ST3, was decreased when high levels of AS mST3 RNA were expressed in these cells. Inversely, we observed that human epithelial MCF7 breast cancer cells, which do not express endogenous ST3, showed significant increased tumorigenicity in nude mice when stably transfected in order to produce mST3 $\left(P<2 \times 10^{-5}\right)$. Similar observation was made using MCF7 cells stably transfected in order to express hST3 at either high levels under the control of the CMV promoter $\left(P<4 \times 10^{-4}\right)$ or at lower levels under the control of the SV40 promoter $\left(P<4 \times 10^{-5}\right)$. These studies showed that the increased tumor incidences induced by either mST3 or hST3 resulted from a shortening of tumor-free periods indicating that, in nude mice, ST3 is involved in tumor formation rather than in tumor growth.

How could ST3 modulate tumor development in nude mice? In vitro analyses of cell proliferation did not show any obvious differences between ST3-expressing and non-expressing cells, suggesting that the observed increase in tumor incidence could not be ascribed to an increased growth rate of ST3-expressing cells. Consistently, once the tumors were established in nude mice, their proliferation rates appeared to be independent of their levels of ST3 expression. In addition, ST3 does not seem to be implicated in cell invasion, since MCF7 cells expressing ST3 did not exhibit any modifications of their capacity to invade interstitial-like or basement membrane matrices. Accordingly, no local invasion or metastatic spreading was detected by histological analysis of tumors, lungs and livers of nude mice injected with ST3-expressing MCF7 cells. Taken together, these findings indicate that ST3 expression did not favor tumor incidence in nude mice by increasing cell proliferation or invasion, but rather by increasing tumor take. This is consistent with our finding that the increase in tumor incidence observed for ST3-expressing MCF7 cells was more pronounced in the first weeks after cell injection. Thus, we propose that ST3 contributes to cell survival and implantation in host tissues. This hypothesis may appear paradoxical with regards to previous observations showing that ST3 was expressed during processes involving epithelial cell apoptosis such as mouse mammary gland involution (25), mouse limb, tail and snout morphogenesis (23) and frog metamorphosis (24). However, while unwanted cells are eliminated during apoptotic events, some neighboring cells are selected for survival (44 and references therein). In this respect, we note that ST3 gene expression is also observed at the time of epithelial cell proliferation occurring in the neoformation of mammary ducts following mammary gland involution (25), in developing limb, tail and snout until birth (23), and in proliferative endometrium (26). Interestingly, comparable observations have been reported for matrilysin, another MMP implicated in cancer progression $(1,3)$. Thus, while SW480 colon cancer cells stably transfected to express matrilysin did not show in vitro any modification of their proliferative or invasive properties, these cells exhibited increased tumorigenicity in vivo, suggesting that the most significant role of matrilysin was at early stage of tumor progression (14).

Tumors that are obtained by S.C. injection of malignant cells into nude mice should be regarded as a model for metastatic implantation rather than for primary tumor development (45). Indeed, S.C. injected cells mimic metastatic cells after extravasation, when these cells have to successfully implant at the metastatic site before being able to proliferate and invade $(45,46)$. This process is dependent upon the cells' capability to survive in host tissues, either in an independent manner or by the recruitment of required factors from their near vicinity. In this context, ST3 may represent a local factor contributing to the survival and implantation of ST3-expressing MCF7 cells S.C. injected in nude mice. It appears reasonable to believe that this might be also the case in human tumors, where ST3 is produced by tumor stromal cells and not by the cancer cells themselves (17-22). ST3 is a secreted protein which is specifically expressed by fibroblastic cells located in the vicinity of cancer cells, suggesting that the same effects should be observed irrespective of the source of the protein. Thus, in human carcinomas ST3 could act as a paracrine host factor contributing to cancer cell survival outside of their compartment of origin. Consistently, in normal embryonic and adult tissues ST3 expression has been reported to occur during tissue remodeling processes, notably when, as in malignant processes, the integrity of the basement membrane which separates epithelial cell compartments from mesenchymal cells showed failure, leading to epithelial/stromal cell contacts $(20,23,25,26)$. Although further studies are required to evaluate this possibility, a role for ST3 in favoring cell survival is consistent with observations demonstrating that high ST3 expression levels were associated with metastatic propensity in human carcinomas $(22,47)$.

\section{Acknowledgments}

We thank P. Chambon for his support and interest in this study. We acknowledge I. Stoll, C. Wendling and S. Vicaire for excellent technical assistance, J. Byrne for critical reading of the manuscript and B. Vrijens for statistical analysis.

This work was supported by funds from the Institut National de la Santé et de la Recherche Médicale, the Centre National de la Recherche Scientifique, the Centre Hospitalier Universitaire Régional, the $\mathrm{Mu}-$ tuelle Générale de l'Education Nationale, the Groupement de Recherches et d'Etudes sur les Génomes (Grant 94/50), the Association pour la Recherche sur le Cancer, the Ligue Nationale Française contre le Cancer and the Comité du Haut-Rhin, the Fondation pour la Recherche Médicale Française, the Fondation de France, and a grant to P. Chambon from the Fondation Jeantet. O. Lefebvre was a recipi- 
ent of a Ph.D. studentship from the Association pour la Recherche sur le Cancer. A. Noël was a recipient of post-doctoral fellowships from the European Community, the Fondation Léon Frédericq, the Fondation Rose et Jean Hoguet, the Fondation cancérologique St. Michel and the Fondation Braconier-Lamarche, all from Belgium.

\section{References}

1. Matrisian, L.M. 1992. The matrix-degrading metalloproteinases. BioEssays. $14: 455-463$

2. Docherty, A.J.P., J. O'Connell, T. Crabbe, S. Angal, and G. Murphy. 1992. The matrix metalloproteinases and their natural inhibitors: prospects for treating degenerative tissue diseases. Trends Biotechnol. 10:200-207.

3. Birkedal-Hansen, H. 1995. Proteolytic remodeling of extracellular matrix. Curr. Opin. Cell Biol. 7:728-735.

4. Freije, J.M.P., I. Diez-Itza, M. Balbin, L.M. Sanchez, R. Blasco, J. Tolivia, and C. Lopez-Otin. 1994. Molecular cloning and expression of collagenase-3, a novel human matrix metalloproteinase produced by breast carcinomas. J. Biol. Chem. 269:16766-16773.

5. Sato, H., T. Takino, Y. Okada, J. Cao, A. Shinagawa, E. Yamamoto, and M. Seiki. 1994. A matrix metalloproteinase expressed on the surface of invasive tumour cells. Nature (Lond.). 230:61-65.

6. Will, H., and B. Hinzmann. 1995. cDNA sequence and mRNA tissue distribution of a novel human matrix metalloproteinase with a potential transmembrane segment. Eur. J. Biochem. 231:602-608.

7. Takino, T., H. Sato, A. Shinagawa, and M. Seiki. 1995. Identification of the second membrane-type matrix metalloproteinase (MT-MMP-2) gene from a human placenta cDNA library. J. Biol. Chem. 270:23013-23020.

8. Alexander, C.M., and Z. Werb. 1991. Extracellular matrix degradation. In Cell Biology of Extracellular Matrix. E.D. Hay, editor. Plenum Press, New York. 8:255-302.

9. Stetler-Stevenson, W.G., S. Aznavoorian, and L.A. Liotta. 1993. Tumor cell interactions with the extracellular matrix during invasion and metastasis. Annu. Rev. Cell. Biol. 9:541-573.

10. Khokha, R., P. Waterhouse, S. Yagel, P.K. Lala, C.M. Overall, G. Norton, and D. Denhardt. 1989. Antisense RNA induced reduction in murine TIMP levels confers oncogenicity on Swiss 3T3 cells. Science (Wash. DC). 243: 947-950.

11. DeClerck, Y.A., N. Perez, H. Shimada, T.C. Boone, K.E. Langley, and S.M. Taylor. 1992. Inhibition of invasion and metastasis in cells transfected with an inhibitor of metalloproteinases. Cancer Res. 52:701-708.

12. Powell, W.C., J.D. Knox, M. Navre, T.M. Grogan, J. Kittelson, R.B. Nagle, and G.T. Bowden. 1993. Expression of the metalloproteinase matrilysin in DU-145 cells increases their invasive potential in severe combined immunodeficient mice. Cancer Res. 53:417-422.

13. Yamamoto, H., F. Itoh, Y. Hinoda, and K. Imai. 1995. Suppression of matrilysin inhibits colon cancer cell invasion in vitro. Int. J. Cancer 61:218-222.

14. Witty, J.P., S. McDonnell, K.J. Newell, P. Cannon, M. Navre, R.J. Tressler, and L.M. Matrisian. 1994. Modulation of matrilysin levels in colon carcinoma cell lines affects tumorigenicity in vivo. Cancer Res. 54:4805-4812.

15. Docherty, A.J.P., M.I. Cockett, M.L. Birch, S. Chander, N. Willmott, J.P. O'Connell, T. Crabbe, A. Mountain, J.R. Morphy, T.A. Millican et al. 1994. Gelatinase inhibitors for treatment of cancer. Clin. Exp. Metast. 12:12.

16. Bernhard, E.J., S. Gruber, and R.J. Muschel. 1994. Direct evidence linking expression of matrix metalloproteinase 9 ( $92 \mathrm{kDa}$ gelatinase/collagenase) to the metastatic phenotype in transformed rat embryo cells. Proc. Natl. Acad. Sci. USA. 91:4293-4297.

17. Basset, P., J.P. Bellocq, C. Wolf, I. Stoll, P. Hutin, J.M. Limacher, O.L. Podhajcer, M.P. Chenard, M.C. Rio, and P. Chambon. 1990. A novel metalloproteinase gene specifically expressed in stromal cells of breast carcinomas. $\mathrm{Na}$ ture (Lond.). 348:699-704.

18. Rouyer, N., C. Wolf, M.P. Chenard, M.C. Rio, P. Chambon, J.P. Bellocq, and P. Basset. 1994. Stromelysin-3 gene expression in human cancer: An overview. Invasion Metastasis. 14:269-275.

19. Basset, P., J.P. Bellocq, P. Anglard, M.P. Chenard, O. Lefebvre, A. Noël, A. Okada, N. Rouyer, M. Santavicca, I. Stoll, C. Wolf, and M.C. Rio. 1995. Stromelysin-3 in breast cancer: the importance of epithelial-stromal interactions during tumor progression. In Breast Cancer: Cellular and Molecular Biology. Vol. V. R.B. Dickson and M.E. Lippman, editors. Boston: Kluwer Academic Publishers. In press.

20. Wolf, C., M.P. Chenard, P. Durand de Grossouvre, J.P. Bellocq, P. Chambon, and P. Basset. 1992. Breast-cancer-associated Stromelysin-3 gene is expressed in basal cell carcinoma and during cutaneous wound healing. J. Invest. Dermatol. 99:870-872.

21. Muller, D., C. Wolf, J. Abecassis, R. Millon, A. Engelmann, G. Bronner, N. Rouyer, M.C. Rio, M. Eber, G. Methlin, P. Chambon, and P. Basset. 1993. Increased stromelysin-3 gene expression is associated with increased local invasiveness in head and neck squamous carcinomas. Cancer Res. 53:165-169.

22. Engel, G., K. Heselmeyer, G. Auer, M. Backdahl, E. Eriksson, and S. Linder. 1994. Correlation between stromelysin-3 mRNA level and outcome of human breast cancer. Int. J. Cancer. 58:830-835.

23. Lefebvre, O., C. Régnier, M.-C. Chenard, C. Wendling, P. Chambon, P. Basset, and M.C. Rio. 1995. Developmental expression of mouse stromelysin-3 mRNA. Development. 121:947-955.

24. Patterton, D., W. Pär Hayes, and Y.B. Shi. 1995. Transcriptional activation of the matrix metalloproteinase gene stromelysin-3 coincides with thyroid hormone-induced cell death during frog metamorphosis. Dev. Biol. 167:252-262.

25. Lefebvre, O., C. Wolf, J.M. Limacher, P. Hutin, C. Wendling, M LeMeur, P. Basset, and M.C. Rio. 1992. The breast cancer-associated stromelysin-3 gene is expressed during mouse mammary gland apoptosis. J. Cell Biol. 119:997-1002.

26. Rodgers, W.H., L.M. Matrisian, L.C. Giudice, B. Dsupin, P. Cannon, C. Sviteck, F. Gorstein, and K.G. Osteen. 1994. Patterns of matrix metalloproteinase expression in cycling endometrium imply differential functions and regulation by steroid hormones. J. Clin. Invest. 94:946-953.

27. Pei, D., G. Majmudar, and S.J. Weiss. 1994. Hydrolytic inactivation of a breast carcinoma cell-derived serpin by human stromelysin-3. J. Biol. Chem. 269:25849-25855.

28. Noël, A., M. Santavicca, I. Stoll, C. L'Hoir, A. Staub, G. Murphy, M.C. Rio, and P. Basset. 1995. Identification of structural determinants controlling human and mouse stromelysin-3 proteolytic activities. J. Biol. Chem. 270: 22866-22872.

29. Pei, D., and S. Weiss. 1995. Furin-dependent intracellular activation of the human stromelysin-3 zymogen. Nature (Lond.). 375:244-247.

30. Baker, S., S. Markowitz, E.R. Fearon, J.K.V. Willson, and B. Vogelstein. 1990. Suppression of human colorectal carcinoma cell growth by wildtype p53. Sciences (Wash. DC). 249:912-915.

31. Green, S., I. Issemann, and E. Sheer. 1988. Versatile in vivo and in vitro eukaryotic expression vector for protein engineering. Nucleic Acids Res. 16:369.

32. Janet, T., G. Labourdette, and B. Pettmann. 1992. Mitogenic growth factors regulate differentially early gene mRNA expression: a study on two clones of 3T3 fibroblasts. Exp. Cell Res. 198:305-314.

33. Chomczynski, P., and N. Sacchi. 1987. Single-step method of RNA isolation by acid guanidinium thiocyanate-phenol-chloroform extraction. Anal. Biochem. 162:156-159.

34. Masiakowski, P., R. Breathnach, J. Block, F. Gannon, A. Krust, and P. Chambon. 1982. Cloning of cDNA sequences of hormone-regulated genes from MCF7 human breast cancer cell line. Nucleic Acids Res. 10:7895-7903.

35. Santavicca, M., A. Noël, M.P. Chenard, Y. Lutz, I. Stoll, J. P. Segain, N. Rouyer, C. Wolf, J.P. Bellocq, and P. Basset. 1995. Characterization of monoclonal antibodies against stromelysin-3 and their use to evaluate stromelysin-3 levels in breast carcinoma by semi-quantitative immunohistochemistry. Int. J. Cancer. 64:336-341.

36. Noël, A., A. Callé, H. Emonard, B. Nusgens, J.M. Foidart, and C.M. Lapière. 1991. Lack of invasion of reconstituted basement membrane matrix by tumor cells. Cancer Res. 51:405-414.

37. Noël, A., N. Simon, J. Raus, and J.M. Foidart. 1992. Basement membrane components (matrigel) promote the tumorigenicity of human breast adenocarcinoma MCF7 cells and provide an in vivo model to assess the responsiveness of cells to estrogen. Biochem. Pharmacol. 43:1263-1267.

38. Cox, D.R. 1972. Regression models and life tables. J. R. Statist. Soc. 187 187-220.

39. Rio, M.C., J.P. Bellocq, B. Gairard, U.B. Rasmussen, A. Krust, C. Koehl, H. Calderoli, V. Schiff, R. Renaud, and P. Chambon. 1987. Specific expression of the pS2 gene in subclasses of breast cancers in comparison with expression of the estrogen and progesterone receptors and the oncogene ERBB2. Proc. Natl. Acad. Sci. USA. 84:9243-9247.

40. Hendrix, M.J.C., E.A. Seftor, R.E.B. Seftor, and I.J. Fidler. 1987. A simple quantitative assay for studying the invasive potential of high and low metastatic variants. Cancer Lett. 38:137-147.

41. Vakaet, L., K. Vleminckx, F. Van Roy, and M. Mareel. 1991. Numerica evaluation of the invasion of closely related cell lines into collagen type I gels. Invasion Metastasis. 11:249-260.

42. Mareel, M., J. Kint, and C. Meyvisch. 1979. Methods of study of the invasion of malignant $\mathrm{C} 3 \mathrm{H}$ mouse fibroblasts into embryonic chick heart in vitro. Virshows Arch. B: Cell Pathol. 30:95.

43. Murphy, G., J.P. Segain, M. O'Shea, M. Cockett, C. Ionnou, O. Lefebvre, P. Chambon, and P. Basset. 1993. The 28-kDa N-terminal domain of mouse stromelysin-3 has the general properties of a weak metalloproteinase. J. Biol. Chem. 268:15435-15441.

44. Raff, M.C., B.A. Barres, J.F. Burne, H.S. Coles, Y. Ishizaki, and M.D. Jacobson. 1993. Programmed cell death and the control of cell survival: lessons from the nervous system. Science (Wash. DC). 262:695-700.

45. Mareel, M., P. DeBaetselier, and F.M. Van Roy. 1990. Bioassays for invasion and metastasis. In Mechanisms of Invasion and Metastases. CRC Press, Boca Raton, FL. 41-72.

46. Rusciano, D., and M.M. Burger. 1992. Why do cancer cells metastasize into particular organs? BioEssays. 14:185-194.

47. Porte, H., E. Chastre, S. Prevot, B. Nordlinger, S. Empereur, P. Basset, P. Chambon, and C. Gespach. 1995. Neoplastic progression of human colorectal cancer is associated with overexpression of the stromelysin-3 and BM-40/ SPARC genes. Int. J. Cancer. 64:70-75. 